\title{
Thymoquinone inhibited vasculogenic capacity and promoted mesenchymal- epithelial transition of human breast cancer stem cells
}

Sanya Haiaty 1,2, Mohammad-Reza Rashidi ${ }^{3}$, Maryam Akbarzadeh ${ }^{2,4}$, Ahad Bazmani ${ }^{5,6}$, Mostafa Mostafazadeh ${ }^{1,2}$, Saba Nikanfar ${ }^{1,2}$, Zohre Zibaei ${ }^{1,6}$, Reza Rahbarghazi ${ }^{3,7,8^{*+}}$ (D) and Mohammad Nouri ${ }^{3,7^{*+}}$

\begin{abstract}
Background: Vasculogenic mimicry (VM) is characterized by the formation of tubular structure inside the tumor stroma. It has been shown that a small fraction of cancer cells, namely cancer stem cells (CSCS), could stimulate the development of vascular units in the tumor niche, leading to enhanced metastasis to the remote sites. This study aimed to study the inhibitory effect of phytocompound, Thymoquinone (TQ), on human breast MDA-MB-231 cell line via monitoring Wnt/PI3K signaling pathway.
\end{abstract}

Methods: MDA-MB-231 CSCs were incubated with different concentrations of TQ for $48 \mathrm{~h}$. The viability of CSCs was determined using the MTT assay. The combination of TQ and PI3K and Wnt3a inhibitors was examined in CSCs. By using the Matrigel assay, we measured the tubulogenesis capacity. The percent of CD24- CSCs and Rhodamine 123 efflux capacity was studied using flow cytometry analysis. Protein levels of Akt, p-Akt, Wnt3a, vascular endothelialcadherin (VE-cadherin), and matrix metalloproteinases-2 and -9 (MMP-2 and -9) were detected by western blotting.

Results: TQ decreased the viability of CSCs in a dose-dependent manner. The combination of TQ with PI3K and Wnt3a inhibitors reduced significantly the survival rate compared to the control group $(p<0.05)$. TQ could blunt the stimulatory effect of vascular endothelial growth factor (VEGF), epidermal growth factor (EGF), fibroblast growth factor (FGF) on CSCs $(p<0.05)$. The vasculogenic capacity of CSCS was reduced after being-exposed to TQ $(p<0.05)$. Western blotting revealed the decrease of CSCS metastasis by suppressing MMP-2 and -9. The protein level of VEcadherin was also diminished in TQ-treated CSCs as compared to the control cell $(p<0.05)$, indicating inhibition of mesenchymal-endothelial transition (MendT). TQ could suppress Wnt3a and PI3K, which coincided with the reduction of the p-Akt/Akt ratio. TQ had the potential to decrease the number of CD24- CSCs and Rhodamine 123 efflux capacity after $48 \mathrm{~h}$.

(Continued on next page)

\footnotetext{
*Correspondence: Rezarahbardvm@gmail.com; rahbarghazir@tbzmed.ac.ir; Nourimd@yahoo.com

${ }^{\dagger}$ Reza Rahbarghazi and Mohammad Nouri contributed equally to this work. ${ }^{3}$ Stem Cell and Regenerative Medicine Institute, Tabriz University of Medical Sciences, Tabriz, Iran

Full list of author information is available at the end of the article
}

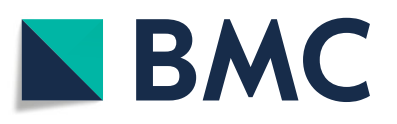

(- The Author(s). 2021, corrected publication 2021. Open Access This article is licensed under a Creative Commons Attribution 4.0 International License, which permits use, sharing, adaptation, distribution and reproduction in any medium or format, as long as you give appropriate credit to the original author(s) and the source, provide a link to the Creative Commons licence, and indicate if changes were made. The images or other third party material in this article are included in the article's Creative Commons licence, unless indicated otherwise in a credit line to the material. If material is not included in the article's Creative Commons licence and your intended use is not permitted by statutory regulation or exceeds the permitted use, you will need to obtain permission directly from the copyright holder. To view a copy of this licence, visit http://creativecommons.org/ licenses/by/4.0/. The Creative Commons Public Domain Dedication waiver (http://creativecommons.org/publicdomain/zero/1. 0/) applies to the data made available in this article, unless otherwise stated in a credit line to the data. 
(Continued from previous page)

Conclusion: TQ could alter the vasculogenic capacity and mesenchymal-epithelial transition of human breast CSCs in vitro. Thus TQ together with anti-angiogenic therapies may be a novel therapeutic agent in the suppression of VM in breast cancer.

Keywords: Thymoquinone, Vasculogenic mimicry, Breast Cancer stem cells, Wnt3a/PI3K signaling pathways

\section{Background}

Breast cancer is touted as the most common mammary gland malignancy in females globally [1]. Numerous attempts have been made to decrease the breast cancer mortality rate in patients with breast cancer but it is still the main cause of mortality in developing and industrialized countries [2]. In solid tumors, the diffusion of oxygen and nutrients is critical to promote the expansion and proliferation of cancer cells [3]. In this regard, the development of de novo blood vessels, so-called angiogenesis, is an efficient way to supply tumor cells' demands [4]. Besides, the expansion of the vascular bed into the tumor mass could facilitate the invasion and metastasis of the remote sites [5]. Angiogenesis is defined as the formation of new blood vessels from the pre-existing vascular network [6-8]. Besides the angiogenesis, a complementary angiogenic mechanism named vasculogenesis and/or VM could promote the formation of vascular structure inside the tumor stroma $[9,10]$. In the process of vasculogenesis different progenitor cells could be recruited to the site of injury and transdifferentiate into mature endothelial cells (ECs) to increase blood supply to the hypoxic cells [11]. Previous studies have confirmed the existence of vasculogenesis in multiple malignancies, such as ductal breast carcinoma, melanoma, etc. [5].

In most circumstances, the conventional therapeutic protocol could not eradicate the cancer cells because of resistance to chemotherapies [12]. It has been shown that a small fraction of cancer cells namely CSCs used different strategies to circumvent the therapeutic approaches and immune cell responses [13]. For example, CSCs have the potential to trans-differentiate into different lineages such as ECs which is termed also MendT. These capacities help CSCs to promote microvascular density in the target cancerous niche [14]. According to previously published data, cells with identical CD24-/ $\mathrm{CD} 44^{+}$markers possess typical CSCs during the progression of breast cancers, leading to poor prognosis [15]. As above-mentioned, breast CSCs like other CSC types could stimulate vascular formation via VM activity [5]. Multiple signaling pathways and effectors such as PI3K, Wnt cascades are closely associated with the VM properties [5, 16, 17]. For instance, it has been shown that PI3K increases VM capacity via the up-regulation of different genes like MT1-MMP and MMP-2, leading to enhanced vasculogenic outcomes [14]. Therefore, the control of angiogenesis signaling pathways in CSCs or cancer ECs could be an efficient approach to inhibit tumor expansion and metastasis [18].

TQ is a natural phyto-compound driven from Nigella sativa Linn has been used in traditional medicine for a variety of complaints in countries from the Mediterranean region to Western Asia [19]. Several studies have indicated that the seeds and oil of TQ have significant anti-parasitic, anti-microbial, anti-oxidant, anti-inflammatory, and immuno-modulatory properties with very low toxicity [20]. Additionally, in vitro and in vivo systems showed the potency of TQ to exert an anticancer activity against various tumor cells via engaging different mechanisms such as anti-angiogenic capacity $[19,21]$.

The exact mechanism of TQ participated in the suppression of breast cancer is the subject of interest. This study aimed to assess the anti-angiogenic capacity of TQ in the human breast MDA-MB-231 cell line. The possible effect of TQ on stemness features and MendT rate were also measured by monitoring the activity of PI3K/ Akt and Wnt/ $\beta$-catenin signaling pathways. We hope that the results of this experiment could help us to understand the underlying mechanisms participating in the tumoricidal activity of the TQ.

\section{Methods}

\section{Cell culture protocol and expansion}

In the current experiment, we used a CSC-like phenotype namely the MDA-MB-231 cell line (NCBI code: C10684). Cells were purchased from Iranian Cell Bank (Pasture Institute, Tehran) and expanded in RPMI 1640 (Gibco, USA) culture medium. The medium was enriched with 10\% FBS (Gibco) and 1\% Pen-Strep (Gibco). Culture flasks containing MDA-MB-231 were maintained at $37{ }^{\circ} \mathrm{C}$ in a humidified atmosphere of $95 \%$ air with $5 \% \mathrm{CO}_{2}$. To passage the cells, we used an enzymatic solution of $0.25 \%$ Trypsin-EDTA (Gibco, USA). Cells at passages 3-6 were subjected to the subsequent experiments.

\section{MTT survival assay}

Treatment of MDA-MB-231 cells with TQ

An initial number of $1 \times 10^{4}$ MDA-MB-231 cells were plated in each well of 96-well plates (SPL, Korea) and incubated under the conventional condition and 
allowed the cells to reach $70-80 \%$ confluence. CSCs were treated with different concentrations of TQ (Cat no: 15039; Cayman; USA) (0.781, 1.562, 3.125. 6.25, $12.5,25,50,100,200$ and $400 \mu \mathrm{M})$ in the culture medium supplemented with 1\% FBS (fetal bovine serum). After completion of the incubation period, the supernatants were discarded and replaced with $30 \mu \mathrm{l} \mathrm{of} 5 \mathrm{mg} / \mathrm{ml} \mathrm{MTT}$ solution (Sigma-Aldrich). The plates were maintained at $37^{\circ} \mathrm{C}$ for $4 \mathrm{~h}$ followed by the addition of the DMSO solution to dissolve the insoluble formazan crystals. The plates were shaken gently for $15 \mathrm{~min}$. Finally, the optical density of each well was measured at $630 \mathrm{~nm}$ using a microplate reader (Hiperion $\mathrm{MPR}^{+}$, Germany). Three sets of MTT assays were conducted. According to previous data, we selected 10 and $30 \mu \mathrm{M}$ TQ for different analyses [22, 23].

\section{Measuring MDA-MB-231 cells viability using Wnt3a and PI3K inhibitors}

To this end, MDA-MB-231 cells were cultured in 96well plates as above-mentioned and pre-treated with Wnt3a (LGK974, Cat no: 14072; Cayman; USA) and PI3K (Ly294002, Cas no: 934389-88-5; SigmaAldrich) inhibitors $24 \mathrm{~h}$ before exposure to 10 and $30 \mu \mathrm{M}$ TQ [24, 25]. Thereafter, cells were kept at $37^{\circ} \mathrm{C}$ for $48 \mathrm{~h}$. Finally, the survival rate was calculated using the MTT assay. This assay was performed in triplicate. Cell viability was expressed as \% of nontreated control cells.

\section{Measuring MDA-MB-231 cells viability after treatment with $T Q$ and VEGF, EGF, and FGF}

Cells were pre-treated with $10,30 \mu \mathrm{M}$ TQ for $48 \mathrm{~h}$ followed by incubation with $10 \mathrm{ng} / \mathrm{ml}$ VEGF (Cat no: C64423; Promocell), FGF (Cat no: F0291; SigmaAldrich), and EGF (Cat no: SRP3027; Sigma-Aldrich) for next $24 \mathrm{~h}$. Finally, the viability of each group was calculated using MTT and expressed as \% of the non-treated control MDA-MB-231 cells.

\section{Tubulogenesis assay}

$50 \mu \mathrm{l}$ pre-cooled growth factor-reduced Matrigel (Cat no: 356230; Corning) was transferred onto each well of a 96-well plate and allowed to solidify at $37^{\circ} \mathrm{C}$. Then, a $200 \mu$ l culture medium containing 1\% FBS and $2.5 \times 10^{4}$ cells pre-treated with TQ was overlaid [26]. The plates were maintained inside the culture incubator and the formation of tubes monitored during the first $24 \mathrm{~h}$. In the current experiment, the tube area, perimeter, and the number was calculated in five random fields using ImageJ software (Version 1.52a). The experiment was performed in triplicate.
Flow cytometric analysis of CD24 in MDA-MB-231 cells after exposure to TQ

TQ-treated cells were collected using a $0.25 \%$ TrypsinEDTA solution and washed twice with PBS (Phosphatebuffered saline) Then, cells were incubated in $100 \mu \mathrm{l}$ PBS with $1 \mu \mathrm{g} / \mathrm{ml}$ of FITC-conjugated CD24 antibody (Order no: 130-095-952; Miltenyi Biotec; Germany) according to the manufacturer's instructions. After twice PBS wash, the percent of $\mathrm{CD} 24^{+}$cells were calculated using BD FACSCalibur and FlowJo software (version 7.6.1).

Flow cytometric analysis of Rhodamine 123 efflux capacity MDA-MB-231 cells $\left(3 \times 10^{5}\right.$ cells/well) were seeded in 6well plates in a culture medium containing $1 \%$ FBS and 10 and $30 \mu \mathrm{M}$. After $48 \mathrm{~h}, 1 \mathrm{mg} / \mathrm{ml}$ Rhodamine 123 (Cas no: 62669-70-9; Sigma-Aldrich) at $37^{\circ} \mathrm{C}$ for $40 \mathrm{~min}$ followed by twice PBS washes. Thereafter, cells were collected and resuspended in $500 \mu \mathrm{l}$ PBS and subjected to the flow cytometry system (BD Bioscience, USA). Data were analyzed using FlowJo software.

\section{Spheroid formation assay}

MDA-MB-231 cells harvested and single-cell suspensions at a density of $1 \times 10^{4}$ cells per $20 \mu \mathrm{l}$ of RPMI culture medium containing $1 \%$ FBS, $0.1 \%$ gelatin carefully placed under the lids of cell culture plate and were inverted over the culture plates. Then the plates were incubated at $37{ }^{\circ} \mathrm{C}$ under a humidified condition with $5 \%$ $\mathrm{CO}_{2}$. After 3 days of incubation, the spheroids formation was monitored by using the inverted microscope (Labomed, USA).

\section{Western blotting}

Both control and treated MDA-MB-231 cells were collected and total protein content was harvested using a protein extraction buffer containing Triton X100, NP40, Tris- $\mathrm{HCl}$, EDTA, NaCl, Sodium Deoxycholate, SDS (sodium dodecyl sulfate), enriched with protease inhibitor cocktail. Lysates were then centrifuged at $12000 \mathrm{~g}$ for 20 $\min$ at $4^{\circ} \mathrm{C}$. Then, the supernatant removed and the concentration of total cellular protein was determined using the Bradford assay. The equal amount of extracted protein was separated by using 10\% SDS-PAGE and transferred to the PVDF membrane. After that, the membranes were blocked with $2 \%$ skim milk at RT for $1 \mathrm{~h}$ and then incubated with primary antibodies: $\beta$-actin (1:300; sc-47,778), VE-cadherin (1:200; sc-52,751), Akt (1:1000; E-AB-30471,), p-Akt (1:100; sc-271,966,), MMP2 (1:200; sc-10,736,), MMP9 (1:100; sc-393,859), Wnt-3a $\left(1: 100 ;\right.$ sc-74,537) at $4{ }^{\circ} \mathrm{C}$ overnight. The next day, membranes were incubated with appropriate HRPsecondary antibodies (1:1000; anti-rabbit sc-2357). The immunoblots were visualized using ECL reagent and X- 
ray films. The density of each band was determined using ImageJ software.

\section{Statistical analysis}

Data are expressed as mean \pm SD. To find the statistical significance, we performed One-Way ANOVA with Tukey post hoc analysis. $p<0.05$ value was considered statistically significant. In the brackets, the significant differences were shown using asterisks as follows; ${ }^{*} p<0.05$; ${ }^{* * *} p<0.01$; ***** $p<0.001$ and ${ }^{* * * * * *} p<0.0001$.

\section{Results}

TQ diminished viability of MDA-MB-231 cells in a dosedependent manner

Cell survival and proliferation are critical events in the dynamic growth of cancer cells. In this line, an MTT assay was performed to assess the possible cytotoxic effect of TQ after $48 \mathrm{~h}$ in vitro. Based on data obtained from the MTT assay, we found that TQ could change the viability of MDA-MB-231 cells in a dose-dependent manner (Fig. 1a). According to our data, the inhibitory effect of TQ was started from 12.5 M TQ compared to the control cells $(p<0.05$; Fig. 1a). Treatment of
CSCs with higher doses (25-400 M TQ) contributed to prominent slop in the viability of cells compared to the control CSCs $(p<0.0001$; Fig. 1a). The results from the MTT panel were the following previously published data [27-29]. In this regard, we selected doses 10 and 30

M TQ for subsequent analyses. Bright-field imaging of cells exposed to 10 and 30 M TQ revealed the morphological changes in MDA-MB-231 cells after $48 \mathrm{~h}$. Based on our evaluation, the control cells exhibited a spindle-like appearance while the exposure of these cells to TQ altered morphological properties indicated by cell detachment and appearance of round-form cells (Fig. 1b). These features were abundant cells compared to the group $10 \mathrm{M}$ TQ.

\section{TQ impaired tubulogenesis capacity of MDA-MB-231 cells} in vitro

To evaluate the impact of TQ on tubulogenesis, MDAMB-231 cells were pre-incubated with two concentrations of TQ $(10,30 \mu \mathrm{M})$ for $24 \mathrm{~h}$ before seeding on Matrigel (Fig. 2a). Bright-field imaging revealed that these cells can be aligned to form tubes on the Matrigel substrate. We noted numerous budding and arborization

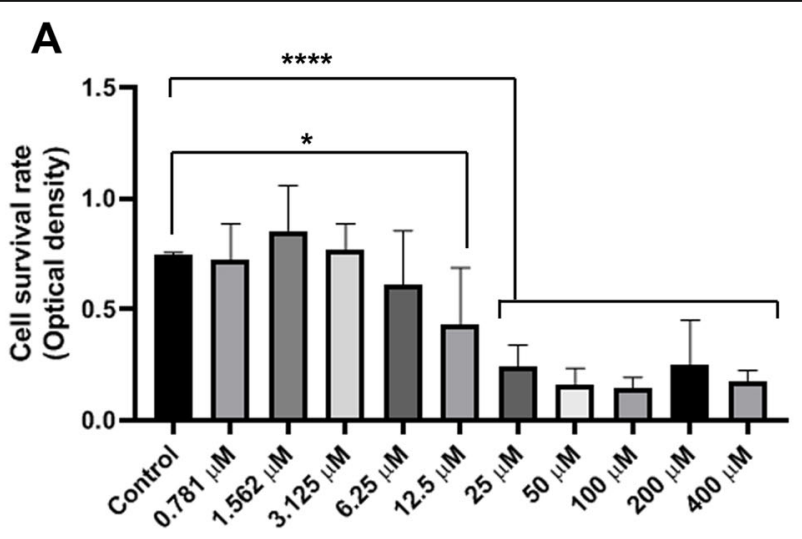

B
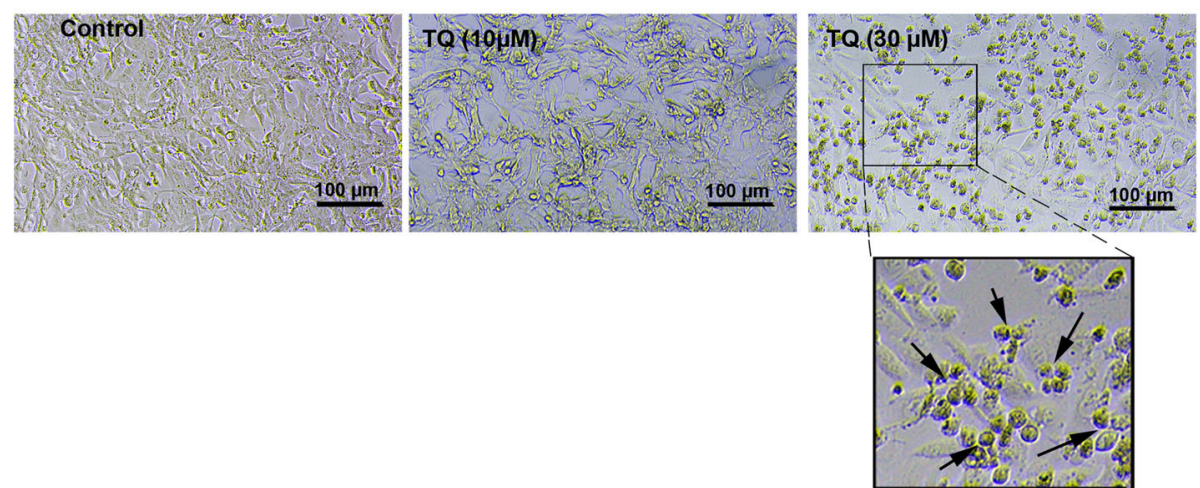

Fig. 1 The viability of MDA-MB-231 triple-negative breast CSCs was evaluated using MTT assay after being exposed to various concentrations of TQ (a). Morphological changes were evaluated in CSCs. Cells lost their elongated shape and acquired round-form after being-treated with 10 and $30 \mu \mathrm{M}$ TQ (b). One-Way ANOVA with Tukey posthoc analysis. ${ }^{*} p<0.05$, and ${ }^{* * *} p<0.0001$ 


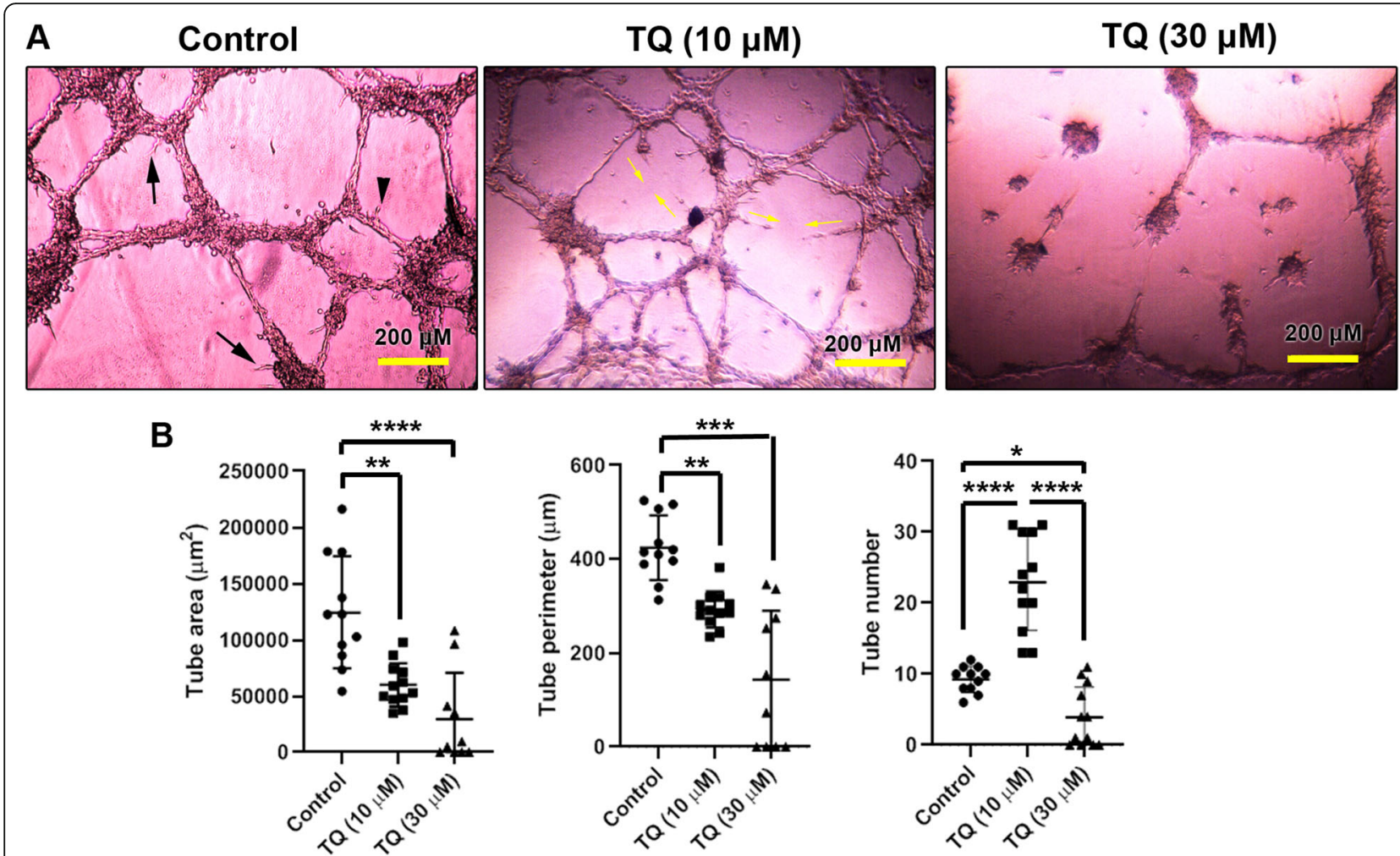

Fig. 2 Measuring tubulogenesis capacity of CSCs on Matrigel substrate (a-b). The inhibitory effect of 10, 30 M TQ was studied on MDA-MB-321 CSCs. Bright-field images showed the inhibition of tubulogenesis activity in CSCs after being-exposed to TQ. Black arrows: cell budding; small yellow arrows: anastomosis. One-Way ANOVA with Tukey posthoc analysis. ${ }^{*} p<0.05,{ }^{* *} p<0.01$; ${ }^{* * *} p<0.001$ and ${ }^{* * *} p<0.0001$

and anastomosis (connection between tubular structures) control cells (black arrows and arrows head). The thickness of tubular walls seems larger compared to groups received 10 and $30 \mu \mathrm{M} \mathrm{TQ}$, showing the potency of TQ to reduce cell alignment in the vascular wall (Fig. 2a). According to our data, the treatment of MDAMB-231 cells with 10 and $30 \mu \mathrm{M}$ TQ led to significant inhibition of tubulogenesis in which all values such as tube area, perimeter, and number were significantly inhibited compared to non-treated control cells $(p<0.05$; Fig. $2 \mathrm{~b})$. Based on our data, TQ could inhibit the angiogenesis capacity of MDA-MB-231 cells in a dose-dependent manner. We found that the treatment of MDA-MB-231 cells with $30 \mu \mathrm{M}$ TQ completely hampered the cell alignment and tube area compared to $10 \mu \mathrm{M} \mathrm{TQ}$. In group $10 \mu \mathrm{M} \mathrm{TQ}$, cells tended to form isolated micro-aggregates indicating the loss of appropriate attachment to beneath substrate. Despite the reduction of angiogenesis values in the $10 \mu \mathrm{M}$ TQ group, cells with the capacity to maintain anastomosis were detectable in Matrigel substrate (yellow arrows). These features show that the incubation of MDA-MB-231 cells with $10 \mu \mathrm{M}$ TQ could not abort the tubulogenesis capacity. Taken together, these data demonstrate that $48-\mathrm{h}$ incubation of MDA-
MB-231 cells with TQ could diminish the tubulogenesis capacity, leading to reduced angiogenesis.

\section{TQ altered Rhodamine 123 efflux and stemness capacity of MDA-MB-231 cells}

The ability of Rhodamine efflux correlates with the ABC transporter function and osmotic pressure [30]. To this end, we performed flow cytometry analysis to measure the function of $\mathrm{ABC}$ transports in MDA-MB-231 cells after being-treated with TQ. Data showed that a small fraction of control cells $(11.4 \pm 7.1 \%)$ are Rhodamine 123-positive after $48 \mathrm{~h}$ while these values increased in TQ-treated groups (Fig. 3a). We observed 30 M TQ significantly increased the percent of Rhodamine positive cells (82.8 $\pm 7.7 \% ; p<0.0001$; Fig. $3 \mathrm{~b})$, indicating Rhodamine accumulation inside the cells. Despite the increase of Rhodamine 123 positive cells in $10 \mathrm{M} \mathrm{TQ}$, the differences did not reach statistically significant levels $(20.4 \pm 3.8 \%$ vs $11.4 \pm 7.1 \%)$, showing appropriate tolerability of MDA-MB-231 cells to the low concentration of TQ. These data highlighted the potency of TQ to alter efflux capacity in MDA-MB-231 cells after $48 \mathrm{~h}$ which could diminish drug resistance capacity in human CSCs. To examine the possible effect of TQ on CSCs stemness, we also performed flow cytometric analysis of 


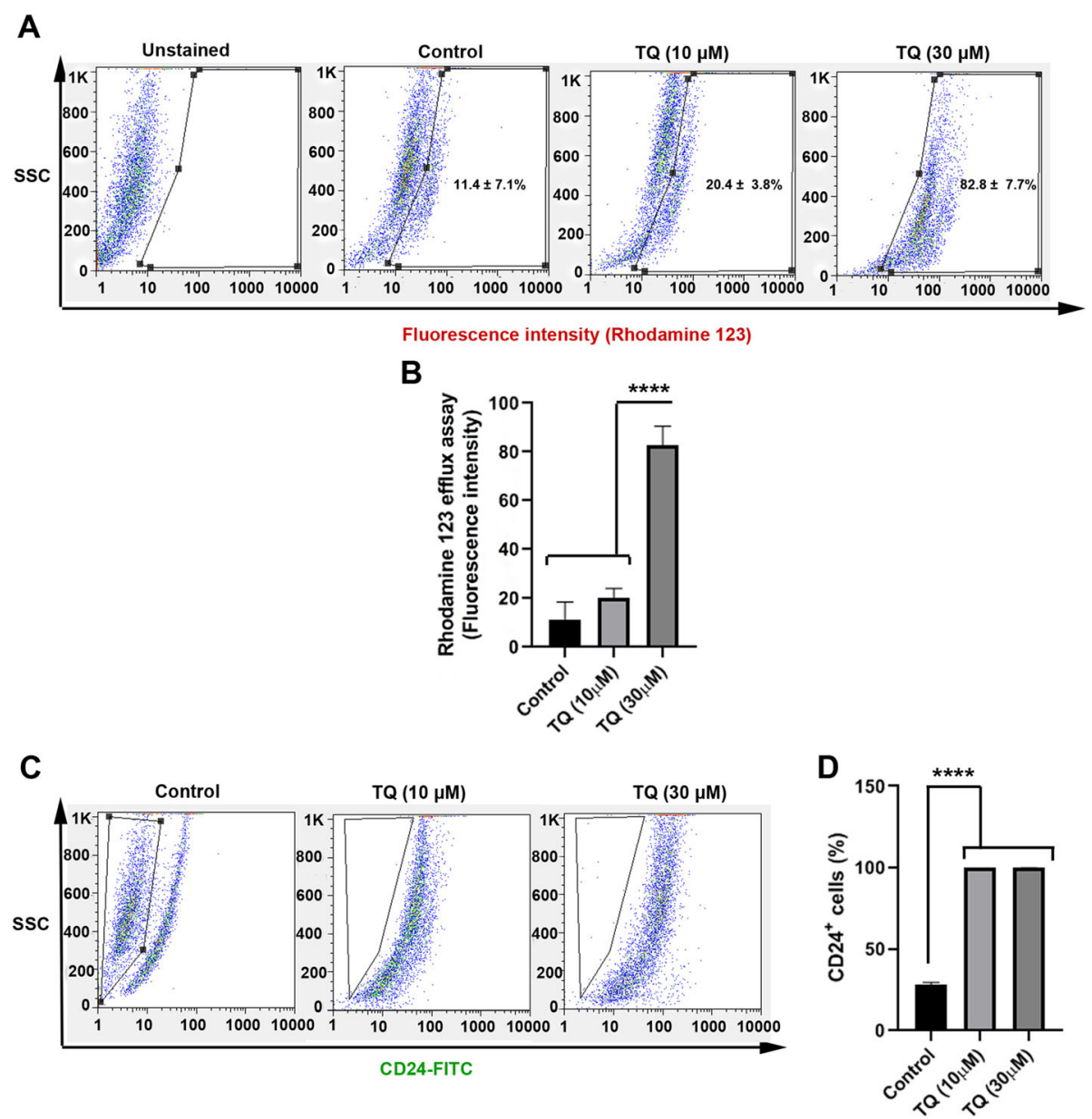

Fig. 3 Flow cytometric analysis of Rhodamine 123 efflux capacity in CSCs after treatment with TQ (a). Treatment with TQ inhibited the Rhodamine 123 efflux capacity and increased accumulated intracellular Rhodamine 123 inside the CSCs (a-b). The percent of CD24- CSCs was also determined using flow cytometry (c). Results showed the increase of $\mathrm{CD}_{24}{ }^{+} \mathrm{CSC}$ and stemness loss in condition containing TQ. One-Way ANOVA with Tukey posthoc analysis. ${ }^{* * *} p<0.0001$

cells based on CD24 (Fig. 3c). In this study, we found that 48-h incubation of CSCs with TQ decreased stemness capacity by reducing the percent of $\mathrm{CD} 24^{+}$cells compared to the control group ( $p<0.0001$; Fig. 3d). Collectively, one could hypothesize that the treatment of MDA-MB-231 cells with TQ could decrease CSC resistance and stemness by modulating the function of the $\mathrm{ABC}$ transporter and protein levels of CD24.

\section{The combined effect of TQ plus PI3K and Wnt3a inhibitors on MDA-MB-231 cells}

In this panel, the combined effects of TQ, PI3K, and Wnt3a inhibitors were studied on the viability of the MDA-MB-231 cells after $48 \mathrm{~h}$. Data showed that TQ could reduce CSCs survival rate in a dose-dependent manner in which $30 \mu \mathrm{M}$ TQ treated cells showed reduced viability compared to the control cells $(p<0.0001$; Fig. 4a, b). We noted that neither PI3K inhibitor nor Wnt3a inhibitor could diminish the viability of CSCs after $24 \mathrm{~h}$. These data show that inhibition of PI3K and Wnt3a are not correlated with the survival rate in human MDA-MB-231 CSCs. The combination of PI3K inhibitors with TQ at a higher dose $(30 \mu \mathrm{M})$ could significantly diminish cell viability as compared to the control group (Fig. 4a). A similar pattern was found in groups treated with Wnt3a inhibitor and $30 \mu \mathrm{M}$ TQ (Fig. 4a). These data show that TQ could decrease the survival rate of CSCs in a dose-dependent manner. Additionally, the reduction of survival rate in groups treated with inhibitors $+\mathrm{TQ}$ could be related to the inhibitory effect of TQ rather than inhibitors' activity.

\section{TQ blunted the stimulatory effect of VEGF, EGF, and FGF on MDA-MB-231 cells}

The potency of different factors such as VEGF, FGF, and EGF was evaluated on the viability of MDA-MB231 cells pre-treated with TQ after $48 \mathrm{~h}$. Data revealed an increased cell survival rate in all groups 

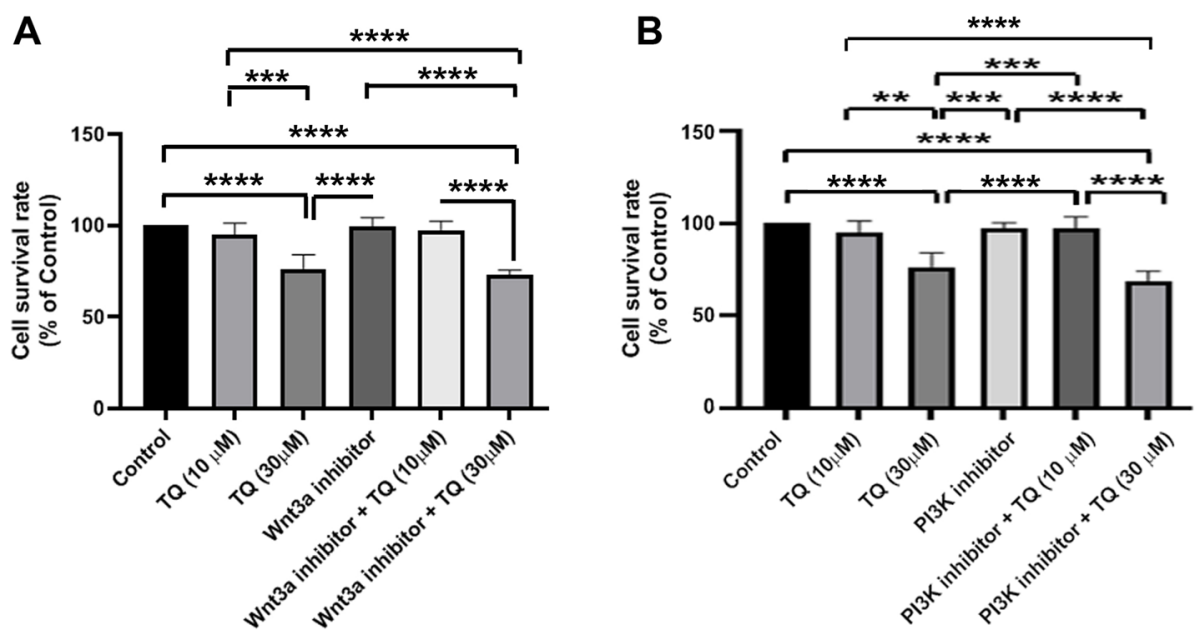

Fig. 4 The combined effects of TQ, PI3K, and Wnt3a were evaluated on the viability of the MDA-MB-231 CSCs using MTT (a-b). Data showed that the combination of PI3K and Wnt3a inhibitors with TQ at a higher dose $(30 \mu \mathrm{M})$ could significantly diminish CSCs viability as compared to the control group. One-Way ANOVA with Tukey posthoc analysis. ${ }^{* *} p<0.01 ;{ }^{* *} p<0.001$ and ${ }^{* * *} p<0.0001$

treated with $10 \mathrm{ng} / \mathrm{ml}$ of VEGF, EGF, and FGF compared to the control group $(p<0.05$; Fig. 5a-b). According to our data, pre-treatment of MDA-MB-231 cells with TQ inhibited the stimulatory effects of all growth factors compared to matched control groups $(p<0.05$; Fig. 5a-b). These data showed TQ has the potential to desensitize CSCs to respond to angiogenic factors, VEGF, and proliferative agents such as EGF and FGF in vitro, showing prophylactic potency of TQ to inhibit different bioactivities of MDA-MB231 cells. To investigate the possible effect of TQ on MDA-MB-231 cells clonogenic capacity, we performed a spheroid formation assay. Based on our observation, these cells could not form microaggregates and spheroids (data not shown).

\section{Combination of TQ with chemical inhibitors suppressed migration capacity and MendT}

To investigate the effect of TQ on MDA-MB-231 cell migration and angiogenic differentiation, we performed western blotting (Fig. 6). The effectors such as PI3K and Wnt3a participate in different activities of cancer cells $[31,32]$. To this end, specific inhibitors of PI3K (Ly294002, $10 \mu \mathrm{M})$ and Wnt3a (LGK974, $10 \mu \mathrm{M})$ were used to treat MDA-MB-231 cells in the presence of TQ. Data indicated that TQ $(10,30 \mu \mathrm{M})$ plus PI3K inhibitor
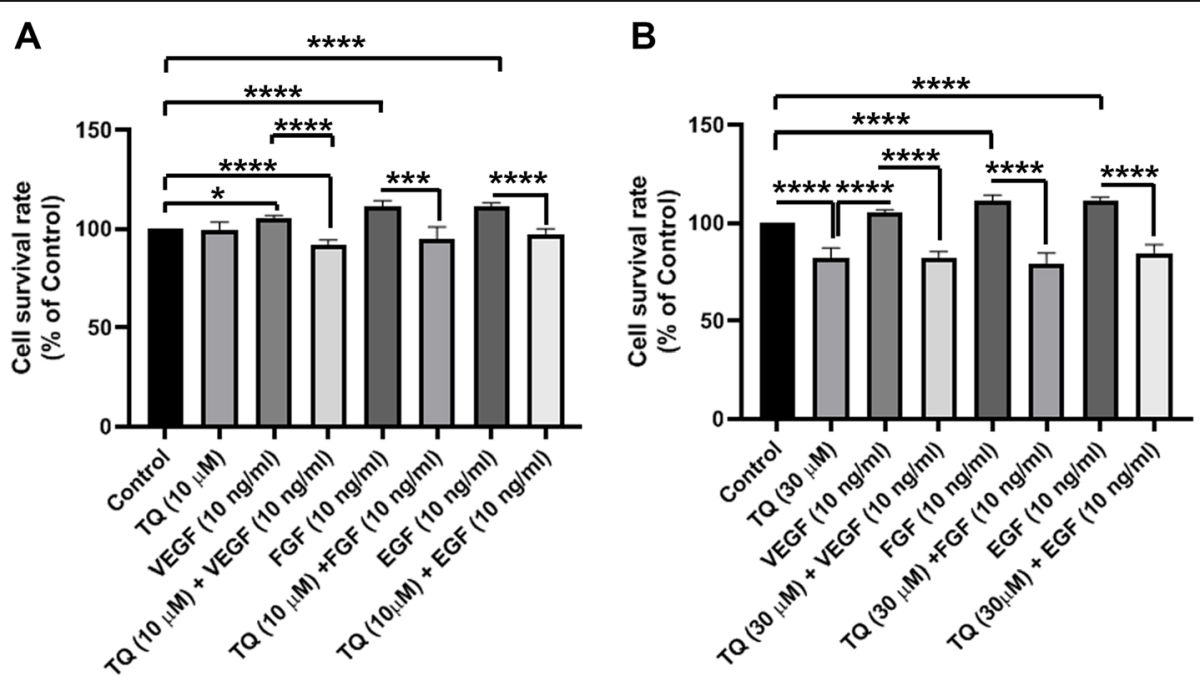

Fig. 5 The stimulatory effect of growth factors such as VEGF, EGF, and FGF was evaluated on the viability of MDA-MB-231 CSCS pre-treated with TQ using MTT assay (a-b). Data showed that pre-treatment of MDA-MB-231 CSCs with TQ inhibited the stimulatory effects of all growth factors compared to matched control groups. One-Way ANOVA with Tukey posthoc analysis. ${ }^{*} p<0.05,{ }^{* *} p<0.01 ;{ }^{* *} p<0.001$ and ${ }^{* * * *} p<0.0001$ 

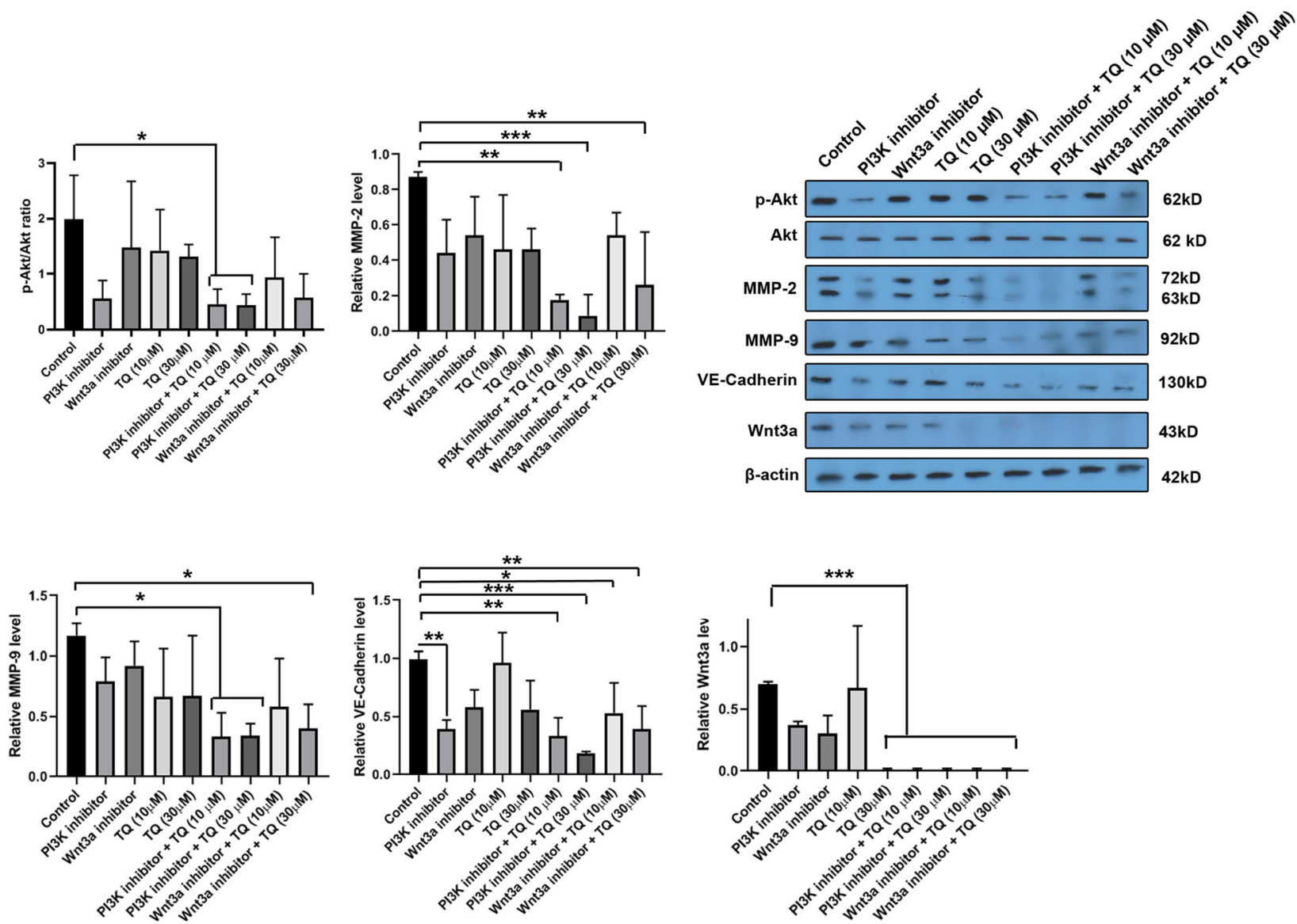

Fig. 6 Western blotting. The combined effects of TQ and PI3K, and Wnt3a inhibitors on the migration and angiogenic differentiation of the MDAMB-231 CSCs. Western blot results showed that TQ could decrease the pAkt/Akt ratio and suppress the protein level of, MMP-2, MMP-9, VEcadherin, Wnt3a in a dose-dependent manner. One-Way ANOVA with Tukey posthoc analysis. ${ }^{*} p<0.05,{ }^{* *} p<0.01 ;{ }^{* * *} p<0.001$

decreased significantly the pAkt/Akt ratio compared to the control group $(p<0.05$; Fig. 6$)$ while the combination of Wnt3a inhibitor with TQ did not alter the pAkt/Akt ratio. Monitoring the levels of MMP-2 and -9 showed a slight decrease, but non-significant, reduction in groups received 10 and $30 \mu \mathrm{M}$ TQ for $48 \mathrm{~h}$. Interestingly, co-treatment of MDA-MB-231 cells with TQ and Wnt3a and PI3K inhibitors suppresses the proteincoding of MMP-2 and -9. In our study, $30 \mu \mathrm{M}$ TQ had superiority to inhibit the synthesis of MMP-2 and -9 compared to the groups $10 \mu \mathrm{M} \mathrm{TQ}$. The vasculogenic potential of MDA-MB-231 cells was also assessed by monitoring endothelial cells specific markers, namely VE-cadherin, after being-treated with TQ for $48 \mathrm{~h}$. Data demonstrated that the incubation of CSCs with PI3K inhibitor, but not Wnt3a inhibitors, hampered MendT of MDA-MB-231 cells by suppressing VE-Cadherin levels compared to non-treated control cells. Although both concentrations of TQ $(10$ and $30 \mu \mathrm{M})$ decreased the levels of VE-cadherin the values did not reach statistically significant compared to the control cells. The combination of two types of inhibitors Ly294002 and LGK974 with TQ could significantly abort MendT capacity in human breast CSCs after $48 \mathrm{~h}$ as compared to the control group. We also noted that the exposure of MDA-MB-231 CSCs with TQ plus Wnt3a inhibitor could reduce protein levels of Wnt3a compared to the control cells. Interestingly, the Wnt3a inhibitor could not significantly diminish the Wnt3a level alone (Fig. 6). Taken together, these data show that TQ could be touted as complementary phyto-compound with tumoricidal activity to alter the protein levels of intracellular effectors such as PI3K and Wnt3a which are important in multiple cancer cells bioactivities such as metastasis and vasculogenic mimicry.

\section{Discussion}

Among various types of anaplastic changes, breast cancer remained one of the highest death cases globally [1]. The promotion of pro-angiogenesis signaling as well as VM seems to be an efficient phenomenon in the development of tumor size, metastasis, and invasion to the 
remote sites [4,5]. Of note, the emergence of CSCs in the tumor niche contributes to resistance against different chemotherapeutic agents such as doxorubicin, etc., leading to high-rate mortality [33-35]. A plethora of scientific literature confirmed the existence of different strategies driven by CSCs to increase the survival of normal cancer cells $[15,18]$. For instance, it has been determined that the CSCs exhibit distinct angiogenic and vasculogenic properties inside the tumor niche by releasing multiple pro-angiogenesis factors and differentiation into endothelial lineage $[5,6]$. In parallel with chemotherapeutic agents, natural products especially phytocompounds are at the center of attention in the prevention and therapy of cancer diseases [5]. TQ is a bioactive component originated from Nigella sativa that has been extensively used in folk medicine against many diseases, including cancers [19]. Here, we investigated the tumoricidal effects of TQ on human MDA-MB-231 CSCs, $\mathrm{CD} 24^{-} / \mathrm{CD} 44^{+}$, after $48 \mathrm{~h}$.

We found that TQ could decrease the viability of MDA-MB-231 cells in a dose-dependent manner after $24 \mathrm{~h}$. Consistent with the current data, Peng and coworkers previously found an increased apoptotic change and the suppression of the NF- B signaling pathway in the human Osteosarcoma SaOS-2 cell line after exposure to the TQ [19]. Other experiments showed the accumulation of reactive oxygen species, suppression of NF-

B, STAT-3 inhibition participate in the suppression of cancer cells in the presence of TQ $[27,36]$. These data showed that TQ could decrease the survival rate of normal cancer cells and CSCs, however, further experiments are needed to discover the mechanism of action of TQ in CSCs.

To the best of our knowledge, the tumoricidal effects of TQ have been investigated in multiple cancer types but there are few experiments correlated with the angiogenesis switch on/off in the CSCs after being-treated with TQ. Commensurate with these comments, the primary aim of this study was to study the antiangiogenesis capacity of TQ on human CSCs. We hypothesize that the inhibition of CSCs angiogenesis and vasculogenesis capacity will help us to slow down the expansion and progression of tumor cells to the other sites. Here, we showed that 48-h incubation of MDA-MB-231 cells with TQ suppressed the tubulogenesis capacity of CSCs on the Matrigel substrate compared to the nontreated control cells. We found the superiority of $30 \mu \mathrm{M}$ TQ in the inhibition of tubulogenesis as compared to the $10 \mu \mathrm{M} \mathrm{TQ}$, showing a dose-dependent activity of TQ in the inhibition of angiogenesis. $30 \mu \mathrm{M}$ TQ had the potential to disrupt the cell-to-cell connection and alignment on the Matrigel surface, leading to the formation of numerous localized micro-aggregates compared to the control and $10 \mu \mathrm{M} \mathrm{TQ}$, the increase of TQ concentration to $30 \mu \mathrm{M}$ diminished the number of budding and arborization. In support of our data, the antiangiogenic effects of TQ have been reported in in vivo zebrafish angiogenesis model and in a xenograft human prostate cancer [21, 29]. Our results indicated that TQ suppressed VE-cadherin levels compared to non-treated control cells.

We also monitored the survival of CSCs in the presence of different angiogenesis growth factors such as FGF, VEGF, and EGF. These factors are pro-angiogenic agents that stimulated cancer cell proliferation and neoangiogenesis inside tumor stroma [37]. Our data showed the increase of CSCs survival after being-treated with these factors. Pre-treatment with $30 \mu \mathrm{M}$ TQ inhibited the stimulatory effect of FGF, VEGF, and EGF in MDAMB-231 cells, showing the lack of cellular response to pro-angiogenesis factors.

The potency of CSCs to exclude different therapeutic agents seems to be correlated to the multipotentiality state [35]. In this regard, it has been shown that the ATP Binding Caste protein $(\mathrm{ABC})$ transporters are highly expressed in these cells which can able these cells to resist again different insulting conditions [38]. To address these issues, we performed a Rhodamine 123 exclusion assay. Data showed that the incubation of CSCs with TQ could blunt the exclusion of Rhodamine 123 compared to the control CSCs. These features coincided with the stemness feature removal and increase of surface membrane-bounded CD24 expression. Previous investigations have revealed a close relationship between the stemness feature (the cellular distribution of CD24, CD44, and CD133) with efflux capacity [34, 39]. Therefore, one could hypothesize that incubation with TQ could sensitize the CSCs via the accumulation of different chemotherapeutic agents.

To understand the participation of signaling pathways inside CSCs to modulate VM after being treated with TQ, we measured the protein levels of PI3K and Wnt3a. Several studies reported that TQ suppressed tumor progression via PI3K/Akt and Wnt3a pathways in various types of cancer [40-43]. We found that the incubation of CSCs with PI3K and Wnt3a inhibitors and TQ could suppress the protein levels of MMP-2 and -9, showing an inhibitory effect of TQ on CSCs migration and metastasis. The incubation of CSCs with inhibitors and TQ alone did not yield statistically significant results compared to the control cells. Therefore, it seems that the combination of TQ with other chemical agents could be a strategy to inhibit the metastasis of CSCs. The blockade of VEGFR2/PI3K/Akt has been shown to suppress the angiogenesis capacity of cancer cells [44]. Here, we also highlighted the decrease of p-Akt/Akt ratio in CSCs after treatment with TQ plus PI3K or Wnt3a inhibitors $[41,42]$. Previously, researchers have proved that TQ 


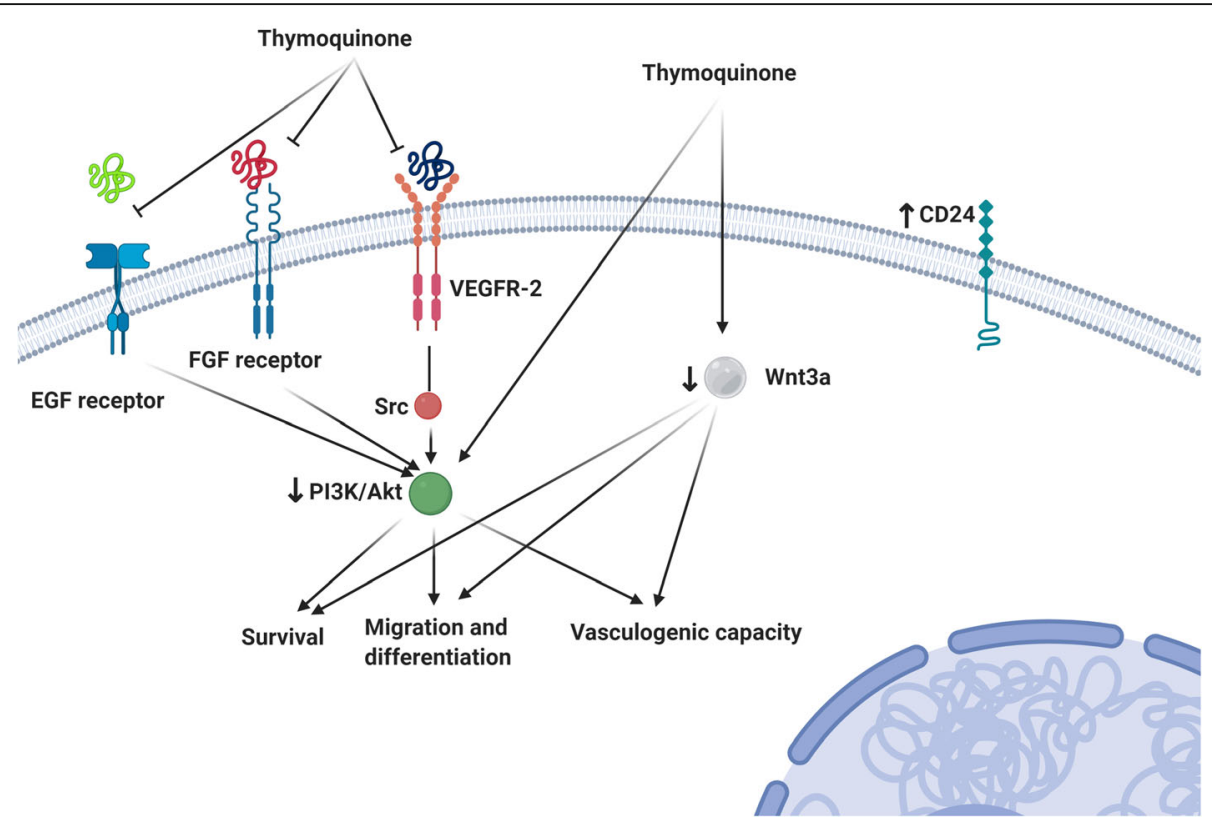

Fig. 7 The possible effect of TQ on human breast cancer via the modulation of different signaling pathways

inhibited tumor growth and angiogenesis through Akt and ERK signaling pathways [29]. It seems that both Wnt3a and PI3K/Akt are two possible pathways involved in CSCs survival and angiogenesis/VM. The potency of MendT capacity was also monitored in MDA-MB-231 cells after being-treated with TQ. Based on our data, TQ in combination with PI3K and Wnt3a inhibitors decreased the protein levels of VE-cadherin, showing the inhibition of CSCs differentiation toward endothelial lineage. The major mechanism of TQ anti-angiogenesis effects is done via the MendT inhibition by PI3K and Wnt3a signaling pathway. Similar to data from the in vitro tube formation assay, western blotting confirmed the inhibition of VE-cadherin in the group that received TQ. VE-cadherin could promote VM network formation through the connection of ECs. VE-cadherin is highly expressed in ECs to stabilize the EC-to-EC connection [45]. Overall, TQ decreased the angiogenic potential of CSCs via the production of VE-cadherin and stemness removal. Interestingly, the critical association of VEcadherin was determined with erythropoietin-producing hepatocellular carcinoma-A2 which in turn could engage the PI3K/Akt signaling pathway [46]. It seems that the inhibition of the PI3K/Akt signaling pathway contributes to pleiotropic effects. It has been shown that the inhibition of this axis could decrease the activity MMP-2, 14 , and the Ln-5y2 chain's cleavage [47]. There are several limitations to our study. It seems that different molecular machinery and signaling pathways are involved in the VM potency of CSCs. Whether these pathways are influenced by TQ is the subject of interest. The efficiency of TQ supplementation along with other chemotherapeutic agents should be monitored in in vivo models.

\section{Conclusions}

Taken together, our results indicated that TQ suppressed VM network formation and metastasis in breast cancer cell line MDA-MB-231 through modulating PI3K, Wnt3a, VE-cadherin pathways which are essential signaling in VM network formation (Fig. 7). Thus TQ together with anti-angiogenic therapies may be a novel therapeutic agent in the elimination of VM in breast cancer.

\section{Abbreviations}

FGF: Basic fibroblast growth factor; CSCs: Cancer stem cells; ECs: Endothelial cells; EGF: Epidermal growth factor; FBS: Fetal Bovine Serum; MMP: Matrix metalloproteinase; MendT: Mesenchymal-to-endothelial transition; MTT: 3-(4, 5-Dimethylthiazol-2-yl)-2, 5-Diphenyltetrazolium Bromide; PBS: Phosphatebuffered saline; TQ: Thymoquinone; VEGF: Vascular endothelial growth factor; VM: Vasculogenic mimicry; SDS: sodium dodecyl sulfate

\section{Acknowledgments}

We special thanks to the Infectious and Tropical Diseases Research Center, Tabriz University of Medical Sciences for their assistance in the progression of my thesis.

\section{Authors' contributions}

S. H., M.A., A. B., M., M., S. N., and Z. Z. performed the experiments and statistical analyses and drafted the manuscript. M. R. supervised appropriate dose selection. R. R. R. and supervised the study M. N. The author (s) read and approved the final manuscript.

\section{Funding}

The research protocol was approved \& Supported by Student Research Committee, Tabriz University of Medical Sciences, Tabriz, Iran (Grant number: 59232). 


\section{Availability of data and materials}

All data generated or analyzed during are included in this published article.

\section{Ethics approval and consent to participate}

All procedures of this study were approved by the Local Ethics Committee of Tabriz University of Medical Sciences (59575).

\section{Consent for publication}

Not applicable.

\section{Competing interests}

The authors declare that they have no competing interests.

\section{Author details}

${ }^{1}$ Student Research Committee, Tabriz University of Medical Sciences, Tabriz, Iran. ${ }^{2}$ Department of Biochemistry and Clinical Laboratories, Tabriz University of Medical Sciences, Tabriz, Iran. ${ }^{3}$ Stem Cell and Regenerative Medicine Institute, Tabriz University of Medical Sciences, Tabriz, Iran. ${ }^{4}$ Department of Biochemistry, Erasmus University Medical Center, Rotterdam, the Netherlands. ${ }^{5}$ Department of Pathobiology, Faculty of Veterinary Medicine, Ferdowsi University Of Mashhad, Mashhad, Iran. ${ }^{6}$ Infectious and Tropical Diseases Research Center, Tabriz University of Medical Sciences, Tabriz, Iran. ${ }^{7}$ Stem Cell Research Center, Tabriz University of Medical Sciences, Imam Reza St., Golgasht St, Tabriz, Iran. ${ }^{8}$ Departmnt of Applied Cell Sciences, Faculty of Advanced Medical Sciences, Tabriz University of Medical Sciences, Tabriz, Iran.

\section{Received: 20 November 2020 Accepted: 11 February 2021}

\section{Published online: 04 March 2021}

\section{References}

1. Zamani ARN, Mashayekhi MR, Jadid MFS, Faridvand Y, Tajalli H, Rahbarghazi R. Photo-modulation of zinc phthalocyanine-treated breast cancer cell line ZR-75-1 inhibited the normal tumor activity in vitro. Lasers Med Sci. 2018; 33(9):1969-78 https://doi.org/10.1007/s10103-018-2563-0.

2. Maroufi NF, Amiri M, Dizaji BF, Vahedian V, Akbarzadeh M, Roshanravan N, Haiaty S, Nouri M, Rashidi MR. Inhibitory effect of melatonin on hypoxiainduced vasculogenic mimicry via suppressing epithelial-mesenchymal transition (EMT) in breast cancer stem cells. Eur J Pharmacol. 2020;881: 173282 https://doi.org/10.1016/j.ejphar.2020.173282.

3. Qi L, Song W, Liu Z, Zhao X, Cao W, Sun B. Wnt3a promotes the Vasculogenic mimicry formation of Colon Cancer via Wnt/beta-catenin signaling. Int J Mol Sci. 2015;16(8):18564-79 https://doi.org/10.3390/ijms 1 60818564

4. Cheraghi O, Dehghan G, Mahdavi M, Rahbarghazi R, Rezabakhsh A, Charoudeh HN, Iranshahi M, Montazersaheb S. Potent anti-angiogenic and cytotoxic effect of conferone on human colorectal adenocarcinoma HT-29 cells. Phytomedicine. 2016;23(4):398-405 https://doi.org/10.1016/j.phymed.2 016.01.015.

5. Haiaty S, Rashidi MR, Akbarzadeh M, Maroufi NF, Yousefi B, Nouri M. Targeting vasculogenic mimicry by phytochemicals: a potential opportunity for cancer therapy. IUBMB Life. 2020;72(5):825-41 https://doi.org/10.1002/ iub.2233.

6. Rahbarghazi R, Nassiri SM, Khazraiinia P, Kajbafzadeh AM, Ahmadi SH, Mohammadi E, Molazem M, Zamani-Ahmadmahmudi M. Juxtacrine and paracrine interactions of rat marrow-derived mesenchymal stem cells, muscle-derived satellite cells, and neonatal cardiomyocytes with endothelial cells in angiogenesis dynamics. Stem Cells Dev. 2013;22(6):855-65 https:// doi.org/10.1089/scd.2012.0377.

7. Amini H, Rezaie J, Vosoughi A, Rahbarghazi R, Nouri M. Cardiac progenitor cells application in cardiovascular disease. J Cardiovasc Thorac Res. 2017; 9(3):127-32.

8. Nemati $S$, Rezabakhsh A, Khoshfetrat AB, Nourazarian A, Avci ÇB, Bagca BG Sardroud HA, Khaksar M, Ahmadi M, Delkhosh A, Sokullu E, Rahbarghazi R. Alginate-gelatin encapsulation of human endothelial cells promoted angiogenesis in in vivo and in vitro milieu. Biotechnol Bioeng. 2017;114(12): 2920-30.

9. Cao Z, Bao M, Miele L, Sarkar FH, Wang Z, Zhou Q. Tumour vasculogenic mimicry is associated with poor prognosis of human cancer patients: a systemic review and meta-analysis. Eur J Cancer. 2013:49(18):3914-23 https://doi.org/10.1016/j.ejca.2013.07.148.
10. Sun B, Zhang S, Zhao X, Zhang W, Hao X. Vasculogenic mimicry is associated with poor survival in patients with mesothelial sarcomas and alveolar rhabdomyosarcomas. Int J Oncol. 2004;25(6):1609-14.

11. Shang B, Cao Z, Zhou Q. Progress in tumor vascular normalization for anticancer therapy: challenges and perspectives. Front Med. 2012;6(1):67-78 https://doi.org/10.1007/s11684-012-0176-8.

12. Dianat-Moghadam $H$, Heidarifard $M$, Jahanban-Esfahlan $R$, Panahi $Y$, Hamishehkar H, Pouremamali F, Rahbarghazi R, Nouri M. Cancer stem cellsemanated therapy resistance: implications for liposomal drug delivery systems. J Control Release. 2018;288:62-83 https://doi.org/10.1016/j.jconrel.2018.08.043.

13. Wang SS, Gao XL, Liu X, Gao SY, Fan YL, Jiang YP, Ma XR, Jiang J, Feng H, Chen QM, Tang YJ, Tang YL, Liang XH. CD133+ cancer stem-like cells promote migration and invasion of salivary adenoid cystic carcinoma by inducing vasculogenic mimicry formation. Oncotarget. 2016;7(20):29051-62 https://doi.org/10.18632/oncotarget.8665.

14. Fathi F, Rezabakhsh A, Rahbarghazi R, Rashidi MR. Early-stage detection of VE-cadherin during endothelial differentiation of human mesenchymal stem cells using SPR biosensor. Biosens Bioelectron. 2017;96:358-66 https://doi. org/10.1016/j.bios.2017.05.018.

15. Lee $\mathrm{CH}$, Wu YT, Hsieh HC, Yu Y, Yu AL, Chang WW. Epidermal growth factor/heat shock protein 27 pathway regulates vasculogenic mimicry activity of breast cancer stem/progenitor cells. Biochimie. 2014;104:117-26 https://doi.org/10.1016/j.biochi.2014.06.011.

16. Qiao L, Liang N, Zhang J, Xie J, Liu F, Xu D, Yu X, Tian Y. Advanced research on vasculogenic mimicry in cancer. J Cell Mol Med. 2015;19(2):315-26 https://doi.org/10.1111/jcmm.12496.

17. Seftor RE, Hess AR, Seftor EA, Kirschmann DA, Hardy KM, Margaryan NV, Hendrix MJ. Tumor cell vasculogenic mimicry: from controversy to therapeutic promise. Am J Pathol. 2012;181(4):1115-25 https://doi.org/10.1 016/j.ajpath.2012.07.013.

18. Pouyafar A, Heydarabad MZ, Abdolalizadeh J, Zade JA, Rahbarghazi R, Talebi M. Modulation of lipolysis and glycolysis pathways in cancer stem cells changed multipotentiality and differentiation capacity toward endothelial lineage. Cell Biosci. 2019;9:30 https://doi.org/10.1186/s13578-019-0293-z.

19. Peng L, Liu A, Shen Y, Xu HZ, Yang SZ, Ying XZ, Liao W, Liu HX, Lin ZQ, Chen QY, Cheng SW, Shen WD. Antitumor and anti-angiogenesis effects of thymoquinone on osteosarcoma through the NF-kappaB pathway. Oncol Rep. 2013;29(2):571-8 https://doi.org/10.3892/or.2012.2165.

20. ElKhoely A, Hafez HF, Ashmawy AM, Badary O, Abdelaziz A, Mostafa A, Shouman SA. Chemopreventive and therapeutic potentials of thymoquinone in HepG2 cells: mechanistic perspectives. J Nat Med. 2015; 69(3):313-23 https://doi.org/10.1007/s11418-015-0895-7.

21. Paramasivam A, Kalaimangai M, Sambantham S, Anandan B, Jayaraman G. Anti-angiogenic activity of thymoquinone by the down-regulation of VEGF using zebrafish (Danio rerio) model. Biomed Prev Nutr. 2012;2(3):169-73 https://doi.org/10.1016/j.bionut.2012.03.011.

22. Abdelwahab SI, Sheikh BY, Taha MM, How CW, Abdullah R, Yagoub U, ElSunousi R, Eid EE. Thymoquinone-loaded nanostructured lipid carriers: preparation, gastroprotection, in vitro toxicity, and pharmacokinetic properties after extravascular administration. Int J Nanomedicine. 2013;8: 2163-72 https://doi.org/10.2147/IJN.S44108.

23. Elmowafy M, Samy A, Raslan MA, Salama A, Said RA, Abdelaziz AE, El-Eraky W, El Awdan S, Viitala T. Enhancement of bioavailability and Pharmacodynamic effects of Thymoquinone via nanostructured lipid carrier (NLC) formulation. AAPS PharmSciTech. 2016;17(3):663-72 https://doi.org/1 0.1208/s12249-015-0391-0.

24. Fraveto A, Cardinale V, Bragazzi MC, Giuliante F, De Rose AM, Grazi GL, Napoletano C, Semeraro R, Lustri AM, Costantini D, Nevi L, Di Matteo S, Renzi A, Carpino G, Gaudio E, Alvaro D. Sensitivity of human intrahepatic Cholangiocarcinoma subtypes to chemotherapeutics and molecular targeted agents: a study on primary cell cultures. PLoS One. 2015;10(11): e0142124 https://doi.org/10.1371/journal.pone.0142124.

25. Iskender B, Izgi K, Canatan H. Novel anti-cancer agent myrtucommulone-a and thymoquinone abrogate epithelial-mesenchymal transition in cancer cells mainly through the inhibition of PI3K/AKT signalling axis. Mol Cell Biochem. 2016;416(1-2):71-84 https://doi.org/10.1007/s11010-016-2697-y.

26. Rezabakhsh A, Montazersaheb S, Nabat E, Hassanpour M, Montaseri A, Malekinejad H, Movassaghpour AA, Rahbarghazi R, Garjani A. Effect of hydroxychloroquine on oxidative/nitrosative status and angiogenesis in endothelial cells under high glucose condition. Bioimpacts. 2017;7(4):219-26 https://doi.org/10.15171/bi.2017.26. 
27. Kundu J, Choi BY, Jeong CH, Kundu JK, Chun KS. Thymoquinone induces apoptosis in human colon cancer HCT116 cells through inactivation of STAT3 by blocking JAK2- and Srcmediated phosphorylation of EGF receptor tyrosine kinase. Oncol Rep. 2014;32(2):821-8 https://doi.org/10.3892/or.2014.3223.

28. Sethi G, Ahn KS, Aggarwal BB. Targeting nuclear factor-kappa B activation pathway by thymoquinone: role in suppression of antiapoptotic gene products and enhancement of apoptosis. Mol Cancer Res. 2008;6(6):1059-70 https://doi.org/10.1158/1541-7786.MCR-07-2088.

29. Yi T, Cho SG, Yi Z, Pang X, Rodriguez M, Wang Y, Sethi G, Aggarwal BB, Liu $M$. Thymoquinone inhibits tumor angiogenesis and tumor growth through suppressing AKT and extracellular signal-regulated kinase signaling pathways. Mol Cancer Ther. 2008;7(7):1789-96 https://doi.org/10.1158/15357163.MCT-08-0124

30. Begicevic RR. Falasca M. ABC transporters in Cancer stem cells: beyond Chemoresistance. Int J Mol Sci. 2017;18(11) https://doi.org/10.3390/ijms18112362.

31. Polakis P. Wnt signaling in cancer. Cold Spring Harb Perspect Biol. 2012;4(5) https://doi.org/10.1101/cshperspect.a008052.

32. Shi X, Wang J, Lei Y, Cong C, Tan D, Zhou X. Research progress on the PI3K AKT signaling pathway in gynecological cancer (review). Mol Med Rep. 2019;19(6):4529-35 https://doi.org/10.3892/mmr.2019.10121.

33. Banerjee S, Padhye S, Azmi A, Wang Z, Philip PA, Kucuk O, Sarkar FH, Mohammad RM. Review on molecular and therapeutic potential of thymoquinone in cancer. Nutr Cancer. 2010;62(7):938-46 https://doi.org/10.1 080/01635581.2010.509832.

34. Moitra K. Overcoming multidrug resistance in Cancer stem cells. Biomed Res Int. 2015;2015:635745 https://doi.org/10.1155/2015/635745.

35. Park JW, Jung KH, Byun Y, Lee JH, Moon SH, Cho YS, Lee KH. ATP-binding cassette transporters substantially reduce estimates of ALDH-positive Cancer cells based on Aldefluor and AldeRed588 assays. Sci Rep. 2019;9(1):6462 https://doi.org/10.1038/s41598-019-42954-9.

36. Ashour AE, Abd-Allah AR, Korashy HM, Attia SM, Alzahrani AZ, Saquib Q, Bakheet SA, Abdel-Hamied HE, Jamal S, Rishi AK. Thymoquinone suppression of the human hepatocellular carcinoma cell growth involves inhibition of IL-8 expression, elevated levels of TRAIL receptors, oxidative stress and apoptosis. Mol Cell Biochem. 2014;389(1-2):85-98 https://doi. org/10.1007/s11010-013-1930-1.

37. Mostofa AGM, Hossain MK, Basak D, Bin Sayeed MS. Thymoquinone as a potential adjuvant therapy for Cancer treatment: evidence from preclinical studies. Front Pharmacol. 2017;8:295 https://doi.org/10.3389/fphar.2017.00295.

38. Dean M, Fojo T, Bates S. Tumour stem cells and drug resistance. Nat Rev Cancer. 2005;5(4):275-84 https://doi.org/10.1038/nrc1590.

39. Jiang ZS, Sun YZ, Wang SM, Ruan JS. Epithelial-mesenchymal transition: potential regulator of $A B C$ transporters in tumor progression. J Cancer. 2017;8(12):2319-27 https://doi.org/10.7150/jca.19079.

40. Lang M, Borgmann M, Oberhuber G, Evstatiev R, Jimenez K, Dammann KW, Jambrich M, Khare V, Campregher C, Ristl R, Gasche C. Thymoquinone attenuates tumor growth in ApcMin mice by interference with Wnt-signaling. Mol Cancer. 2013;12(1):41 https://doi.org/10.1186/1476-4598-12-41.

41. Ndreshkjana B, Capci A, Klein V, Chanvorachote P, Muenzner JK, Huebner K, Steinmann S, Erlenbach-Wuensch K, Geppert Cl, Agaimy A, Ballout F, El-Baba C, Gali-Muhtasib H, Roehe AV, Hartmann A, Tsogoeva SB, Schneider-Stock R. Combination of 5-fluorouracil and thymoquinone targets stem cell gene signature in colorectal cancer cells. Cell Death Dis. 2019;10(6):379 https:// doi.org/10.1038/s41419-019-1611-4.

42. Rajput S, Kumar BN, Sarkar S, Das S, Azab B, Santhekadur PK, Das SK, Emdad L, Sarkar D, Fisher PB, Mandal M. Targeted apoptotic effects of thymoquinone and tamoxifen on XIAP mediated Akt regulation in breast cancer. PLoS One. 2013;8(4):e61342 https://doi.org/10.1371/journal.pone.0061342.

43. Xu D, Ma Y, Zhao B, Li S, Zhang Y, Pan S, Wu Y, Wang J, Wang D, Pan H, Liu L, Jiang $\mathrm{H}$. Thymoquinone induces G2/M arrest, inactivates PI3K/Akt and nuclear factor-kappaB pathways in human cholangiocarcinomas both in vitro and in vivo. Oncol Rep. 2014;31(5):2063-70 https://doi.org/10.3892/or.2014.3059.

44. Mojzis J, Varinska L, Mojzisova G, Kostova I, Mirossay L. Antiangiogenic effects of flavonoids and chalcones. Pharmacol Res. 2008;57(4):259-65 https://doi.org/10.1016/j.phrs.2008.02.005.

45. Pouyafar A, Rezabakhsh A, Rahbarghazi R, Heydarabad MZ, Shokrollahi E, Sokullu E, Khaksar M, Nourazarian A, Avci ÇB. Treatment of cancer stem cells from human colon adenocarcinoma cell line HT-29 with resveratrol and sulindac induced mesenchymal-endothelial transition rate. Cell Tissue Res. 2019;376(3):377-88 https://doi.org/10.1007/s00441-019-02998-9.
46. Kim HS, Won YJ, Shim JH, Kim HJ, Kim BS, Hong HN. Role of EphA2-PI3K signaling in vasculogenic mimicry induced by cancer-associated fibroblasts in gastric cancer cells. Oncol Lett. 2019;18(3):3031-8 https://doi.org/10.3892/ ol.2019.10677.

47. Lu XS, Sun W, Ge CY, Zhang WZ, Fan YZ. Contribution of the PI3K/MMPS/ Ln-5Y2 and EphA2/FAK/Paxillin signaling pathways to tumor growth and vasculogenic mimicry of gallbladder carcinomas. Int J Oncol. 2013;42(6): 2103-15 https://doi.org/10.3892/ijo.2013.1897.

\section{Publisher's Note}

Springer Nature remains neutral with regard to jurisdictional claims in published maps and institutional affiliations.
Ready to submit your research? Choose BMC and benefit from:

- fast, convenient online submission

- thorough peer review by experienced researchers in your field

- rapid publication on acceptance

- support for research data, including large and complex data types

- gold Open Access which fosters wider collaboration and increased citations

- maximum visibility for your research: over $100 \mathrm{M}$ website views per year

At $\mathrm{BMC}$, research is always in progress.

Learn more biomedcentral.com/submissions 